\title{
Pilot Testing a Robot for Reducing Pain in Hospitalized Preterm Infants
}

Nicholas Williams MBBS ${ }^{1}$, Karon MacLean $\mathrm{PhD}^{2}$, Ling Guan MD, MSc, $\mathrm{PhD}^{1}$, Jean Paul Collet MD, $\mathrm{PhD}^{1}$, Liisa Holsti PhD $1,3,4,5$

1) Department of Paediatrics, University of British Columbia, Vancouver, Canada

2) Department of Computer Science, University of British Columbia, Vancouver, Canada

3) Department of Occupational Science and Occupational Therapy, University of British Columbia, Vancouver, Canada

4) B.C. Children's Hospital Research Institute

5) B.C. Women's Hospital Research Institute

\section{Corresponding author:}

Name: Dr. Liisa Holsti

Address: Clinical Support Building, V3-327, 950 West 28 ${ }^{\text {th }}$ Avenue, Vancouver, BC, V5Z 4H4. Email: liisa.holsti@ubc.ca

Telephone: 604-875-2000 ext 5200

Fax: 604-875-3212

Trial Registration Number: www.ClinicalTrials.gov: NCT01433588

Acknowledgements: We would like to thank Mary Beckingham and Alice van Zanten for completing the recruitment and data collection for the study. We would also like to thank the families who agreed to be part of this study.

Funding: Funding for this study was provided by the B.C. Children's Hospital Research Institute and the University of British Columbia Faculty of Medicine. LH is supported by a Canadian Institutes of Health Research Canada Research Chair in Neonatal Health and 
Development.

Conference Presentations: This work has been presented twice at conferences in abstract form: Williams N, Holsti L, MacLean K, Collet JP. Calmer: A novel approach for reducing stress in preterm infants. Pediatric Academic Society, E-PAS2016:2881.620. Baltimore USA, May, 2016 and Holsti L, Williams N, MacLean K, Collet JP. Calmer: A novel approach for reducing stress in preterm infants. Canadian Association of Occupational Therapy. Vancouver, Canada. Platform Presentation. June 22, 2018.

Conflicts of Interest: Authors Drs. MacLean and Holsti are inventors of the Calmer medical device for pain management for preterm infants. In partnership with the Provincial Health Services Association of British Columbia, Canada, we could, in the future, receive royalties as a result of licensing agreements made with private industry for commercialization of the device. We have not received any remuneration to date. In addition, we did not participate actively in the data analysis in this paper so as to remain at arms-length. None of the other authors have relationships with any sponsoring organization or a for-profit interests the organization represents, or with any for-profit product discussed or implied in the text of the our manuscript. Ethics Approval: The study was approved by the Clinical Research Ethics Board of the University of British Columbia and the Children's and Women's Health Centre of British Columbia Research Review Committee (Certificate \# H11-01968). 


\begin{abstract}
Introduction: Optimizing neurodevelopment is a key goal of neonatal occupational therapy. In preterm infants, repeated procedural pain is associated with adverse effects on neurodevelopment long term. Calmer is a robot designed to reduce infant pain. Objective: To examine the effects of Calmer on heart rate variability (HRV) during routine blood collection in preterm infants. Methodology: In a randomized controlled pilot trial, 10 infants were assigned to either Standard Care $(n=5$, Facilitated tucking $[F T])$ or Calmer treatment $(n=5)$. HRV was recorded continuously and quantified using the area (power) of the spectrum in high and low frequency (HF: 0.150.40Hz/ms 2 ; LF: $0.04-0.15 \mathrm{~Hz} / \mathrm{ms}_{2}$ ) regions. Changes in HRV during three, two-minute phases (Baseline, Heel Poke and Recovery) were compared between groups. Results: Calmer infants had $90 \%$ greater parasympathetic activation ([PS] reduced stress) during Baseline, $82 \%$ greater PS activation during Poke, and 24\% greater PS activation during Recovery than FT infants. Conclusion: Calmer reduced physiological preterm infant pain reactivity during blood collection.
\end{abstract}




\section{Introduction}

Defined as infants born at less than 37 weeks gestation, the latest estimate of the annual worldwide number of preterm infants born was approximately 15 million (Howson, Merialdi, Lawn, Requejo, \& Say, 2009). The vast majority of these infants require admission to a neonatal intensive care unit (NICU) where they undergo many necessary painful or stressful care-related procedures, such as blood tests. In fact, during their time in the Neonatal Intensive Care Unit (NICU), these infants are routinely exposed to 5-15 painful procedures (e.g., blood tests) each day particularly during the first weeks of life; exposure can be as high as 300-400 procedures over an admission (Roofthooft, Simons, Anand, Tibboel, \& Van Dijk, 2014). Occupational therapists are concerned about the effects of neonatal pain because it is an independent risk factor for sub-optimal brain development and occupational performance outcomes long term (Holsti, 2012). Specifically, repeated early pain exposure is associated with damaged brain microstructure and processing (Brummelte, et al., 2012; Doesburg, et al., 2013; Zwicker, et al., 2013a), with ongoing altered programming of stress-arousal systems (Grunau, Holsti, \& Peters, 2006; Holsti, Weinberg, Whitfield, \& Grunau, 2007), and with poorer motor and cognitive outcomes (Grunau, et al., 2009; Zwicker et al., 2013a; Zwicker et al., 2013b).

For these infants, severe pain (e.g. surgery) is treated with pharmacological analgesics (Stevens, Gibbins, \& Franck, 2000). However, these medications are not effective for treating pain associated with routine painful procedures (e.g. blood tests) (Carbajal, Lenclen, Jugie, \& et, 2005). Moreover, pharmacological agents have negative side effects and a lack of clarity exists about associations between early use and adverse long-term neurodevelopmental outcomes (Holsti, Zwicker, \& Grunau, 2016; McPherson \& Grunau, 2014). 
Current best practice is to treat less severe neonatal pain with non-pharmacological or behavioral strategies, such as sucrose. However, concerns regarding the long-term use of sucrose have emerged (Holsti \& Grunau, 2010; Trembley, et al., 2016). Instead, sensory-based treatments related to human touch remain well tested viable alternatives, such as skin-to-skin holding, or facilitated tucking (Campbell-Yeo, Fernandes, \& Johnston, 2011; Johnston, et al., 2014).

Occupational therapists working in NICUs have specialized knowledge regarding accurate identification of neurodevelopmental signs of stress and stability (e.g. specific body movements such as finger splay or bringing hands to mouth and/or changes in muscle tone) (Holsti, \& Grunau, 2007b.). Signs such as these have been integrated into tools which improve the assessment of pain in these high risk infants (Holsti \& Grunau, 2007a; Holsti, \& Grunau, 2007b). Central to this study, occupational therapists also devise therapeutic interventions that are brain protective and that promote preterm infants' optimal social-emotional, physical, cognitive and sensory development, including those which are founded on human touch which can be used to manage neonatal pain (Holsti, Oberlander, \& Brant, 2011; Vergara, et al., 2006).

Of the aforementioned strategies, skin-to-skin holding provides multiple benefits for improving outcomes related to growth and development along with those related to pain mitigation. Each component of skin-to-skin holding (e.g. touch, warmth, heart beat sounds, breathing motion) simultaneously activates multiple opioid and non-opioid pathways (Johnston, Fernades, \& Cambell-Yeo, 2011; Johnston, Filion, \& Campbell-Yeo, 2008).

A second, human touch-based treatment used for pain mitigation in preterm infants is facilitated tucking. Facilitated tucking is a holding strategy whereby a parent or other caregiver provides gentle but firm containment of an infant's limbs before, during and after a painful 
procedure (Holsti, Backman \& Engel, 2013). Facilitated tucking has been shown to reduce standardized pain indices by $20-30 \%$ during endotracheal suctioning (Ward-Larson, Horn \& Gosnell, 2004) and heel lance (e.g. Axelin, Salantera, \& Lehtonen, 2006).

One of the ways in which skin-to skin holding specifically is thought to be effective for pain reduction is that it activates the parasympathetic nervous system (PS), part of the autonomic nervous system (ANS). Measuring the PS system can be done through assessing cardiovascular reactivity to stressful events. Indeed, along with changes in behavioral indices, heart rate (HR) is the most easily accessed, valid, physiological index of preterm infant pain/stress responses (Waxman, et al., 2016). However, the global measure of HR can be moderated by many factors, such as blood pressure and body temperature. Using the more sensitive indicator, heart rate variability (HRV), reveals components of the underlying central neurologic control system in response to painful/stressful stimuli (Stevens, Pillai Riddell, \& Oberlander, 2007).

HRV is calculated by measuring multiple values of the inter-beat interval (the interval between consecutive beats of an individual's heart) over a specific time period and applying a mathematical operation to these values. In particular, researchers have found, using frequency domain methods (e.g., Fast Fourier Transformation), that the power within frequency bands of the HRV can be used to determine stress. HRV may be measured in Hertz per milli-seconds squared $\left(\mathrm{Hz} / \mathrm{ms}^{2}\right)$ (e.g. Oberlander and Saul, 2002).

HRV is regulated by both the sympathetic (SP: activating) and PS (stress-relieving) nervous systems. Healthy individuals have a balance between SP and PS systems and are able to have high variability between systems allowing adaptive flexibility to environmental stressors. Recent research shows that in particular PS activation is particularly important for health. For example, in adults, reduced PS activation (less ability to relieve stress) is associated with 
increased inflammation, cardiovascular disease, cancer and Type 2 diabetes (Borovikova, et al., 2000; Huston \& Tracey, 2011; Parrish, et al., 2008).

For preterm infants, noting changes in HRV is becoming a standard clinical indicator of infection (Moorman, et al., 2011; Snedec, et al., 2013) . With respect to the effects of human touch-based treatments on preterm infant HRV, massage has been shown to increase PS activity (Smith, et al., 2013; Smith, Haley, Slater, \& Moyer-Mileur, 2013). Specifically related to our study, two reports show that skin-to-skin holding during blood collection induces a more balanced and stable HRV response (Cong, Ludington-Hoe, McCain, \& Fu, 2009; Cong, et al., 2012) .

Despite the many benefits of skin-to skin holding, numerous barriers make the implementation of this strategy challenging. For example, parents are not always available (Frank \& Spencer, 2003). Furthermore, because of regionalized neonatal intensive care, some preterm infants are cared for far from their homes, and often many infants are not medically stable enough to be held for long periods.

To address this gap, we invented a novel prototype medical device called Calmer (PCT Utility Patent \# CA2015/051002) that simultaneously delivers fundamental components of skinto-skin holding (touch, breathing motion and sound), which activate parallel physiological pathways to reduce pain. Calmer has an artificial skin-like surface, vertical movement that mimics a breathing motion, and heart-beat sounds. The breathing motion and heart sounds can be individually programmed to match those of each infant's caregivers' resting respiratory and heart rates. A key benefit of the design is that Calmer's completely non-humanoid appearance avoids staff and family perceptions that it is "replacing the parent"; instead, Calmer was meant to be used as a valuable adjunct to other types of care ). Key 
components of the design included not only the pain mitigating factors, but also included considerations regarding the ergonomic effects on the caregivers of installing a robotic platform into an incubator-another area in which occupational therapists contribute (results of user experience and acceptance are being published elsewhere)

As a first step in technology transfer, the aim of this pilot, randomized controlled study was to evaluate the initial efficacy of using Calmer for reducing pain-induced stress experienced by preterm infants undergoing a care-related procedure. Our hypothesis was that during acute pain (defined as a skin-breaking procedure-blood collection), infants on Calmer before, during and immediately after the blood collection would have lower mean heart rates, greater activation of parasympathetic modulation and greater overall heart rate variability than infants who received our standard of care, facilitated tucking, a human touch based treatment.

\section{Methods:}

Patients: Infants were recruited by a NICU-trained research nurse; written informed consent was obtained from the mother or other legal guardian according to the research protocol approved by the Clinical Research Ethics Board and the Research Review Committee. All

procedures followed were in accordance with the ethical standards of the and consistent with the revised (2000) Helsinki Declaration. Appropriate informed consent procedures were used throughout the study and all participants' consenting parents/legal guardians were informed of the study's risks and benefits. Each family consenting understood that their infants participation was voluntary, and parents/legal guardians were informed by consent that they and their infants identity would not be disclosed. Appropriate handling of 
confidentiality and data security was maintained throughout and after the study as per Ethics Board rules.

Infants admitted to the NICU with a gestation age (GA) between 27 and 36 weeks and who were due to undergo a routine blood test (heel lance) required for clinical care were assigned randomly to either receive standard care, facilitated tucking (FT) or Calmer treatment. Infants with congenital anomalies, who were higher order multiple births (e.g. triplets), had a history of maternal abuse of controlled drugs and substances, had ongoing infection, or had undergone any type of surgery were excluded. In addition, infants who had received pharmacological analgesics or sedatives within 72 hours of the assessment or who had blood collection that occurred beyond the $36^{\text {th }}$ completed week GA ( 36 weeks +6 days) were excluded from the study.

\section{Intervention Procedures}

Both Groups (Baseline and Recovery Phases): Infants in the Calmer group were transferred gently to the Calmer platform, which was stationary, and settled so that infants in both groups were left undisturbed in their cots for 40 minutes in prone position with rolls around the body to promote a flexed position and to ensure a stable Baseline phase. Infants were placed in prone so as to replicate the body position they would have were they to have been held in skin-to-skin contact with their mothers. For the Recovery phases, defined as after the last contact of the lab technician, the infants in the Calmer group continued to be exposed to the treatment for 10 minutes to ensure a stable recovery time was achieved. We recorded this length of time as a conservative approach as we have found in other studies that full behavioral and physiological recovery can take up to 5 minutes (Morison, et al., 2003). 
Facilitated Tucking Group (Intervention Phase): The use of facilitated tucking and a soother is the standard of care for managing acute minor painful procedures in our NICU. Two minutes before the heel lance, the research nurse administered facilitated tucking (as described in the introduction) and the soother. She continued to hold the infant until the blood collection was complete and the infant was in a stable state (up to a maximum of 10 minutes) and ensured that the soother was held in the infant's mouth so that continuous oral contact was maintained. Calmer Group (Intervention Phase): On the day of the study, the research nurse recorded from the infants' mother a two, one-minute periods of heart and respiratory rate after the mother had sat and rested quietly for 15 minutes. The one-minute average of the two periods was used to program the Calmer. Then, fifteen minutes before the first contact by the lab technician, the Calmer breathing and heart rate sounds were started. Two minutes before the blood collection, each infant was given a soother, which, as for the standard care group, was maintained in the mouth throughout the blood collection period by the research nurse. We chose 15 minutes of continuous exposure on Calmer before blood collection as this period is the minimum time parents would hold their infants were they to provide skin-to-skin holding for pain management (Johnston, Filion, \& Campbell-Yeo, 2008).

Randomization: Subject allocation was based on a sequence of computer-generated random numbers. Twins were randomized as individuals. Access to the randomization list was through a web-based system (REDCAP) that enabled online interactive checking of the inclusion/exclusion criteria before authorizing random allocation. The trial coordinator initiated the randomization process and received the information regarding group allocation that guided the intervention. In order to avoid randomizing infants who did not go on to have blood collected, infants were 
allocated to treatment groups as close to the intervention as possible to still allow taking of physiological measures from each infant's parent.

Outcome Measure: HRV was recorded continuously beginning 5 minutes before (Baseline), throughout (Poke) and 10 minutes after (Recovery) blood collection. HR was recorded from a single lead surface ECG (lead II) (Biopac, CA) and digitally sampled at $1000 \mathrm{~Hz} / \mathrm{sec}$. The single lead was attached to the three ECG patches already in place on the infant as per our NICU nursing protocol; two of the ECG patches were on the front aspect of both sides of each infant's chest and one on the abdomen. The ECG signal could then be diverted from the infants' bedside monitor to a research ECG monitor on the research study cart at the bedside. Custom physiologic signal processing software (MindWare, USA) was used to analyze 2-minutes of stable periods of data. A stable period of data was defined as one having minimal variation in mean and variance of the data (Oberlander \& Saul, 2002). Stable data was picked as close as possible to the following phase markers which were time stamped on the recording with an electronic foot pedal: two minutes just before the first contact of the lab technician (Baseline), two minutes immediately after the skin break of the heel lance/squeeze (Lance), and two minutes a the beginning of the Recovery phase. Power spectra was calculated for each study phase. HRV was quantified using the area (power) of the spectrum in high frequency (HF: $0.15-0.80 \mathrm{~Hz} / \mathrm{ms}^{2}$ ) regions. HF power represents the parasympathetic (PS) activity; decreased HF is a sign of stress and increased HF power is a sign of stress recovery, or calmness and is mediated through vagal nerve activity (Oberlander \& Saul, 2002). Low frequency power (LF: 0.04-0.15 Hz/ms ${ }^{2}$ regions) represents both PS and sympathetic activity combined (Oberlander \& Saul, 2002). Changes in HRV power across the 3 procedure phases were compared between groups. The results were evaluated by team members who are expert in HRV analyses, but who were not involved in 
either the recruitment, randomization, or data collection and who were blind to study group characteristics (JPC, LG).

Demographics: Chart reviews were conducted by the NICU research nurse to collect maternal demographic and clinical information regarding the infant from birth to day of testing including the following: birth weight, GA at birth, numbers and types of invasive skin breaking procedures, maternal education (in years), time of last feeding just before blood collection. This data was used for descriptive purposes.

Data Analysis: Descriptive analyses for calculating medians and inter-quartile ranges for the demographic variables and for the HRV responses was completed using Microsoft Excel, 2011. Interquartile range (IQR) is a measure of variability, based on dividing a data set into quartiles.

\section{Results:}

Fourteen infants were randomized for the pilot study. Of these, data from four infants were not included in the analyses because of either technical issues with Calmer (the platform stopped running [one infant]) or with the HRV recordings ( 3 infants) leaving 10 infants; 5 into each the Calmer and FT groups (See Patient Flow Diagram Figure 1).

The median [IQR] gestation age and birth weight of the infants in the FT group was 28.1 [27.228.9] weeks and 1235 [1194-1390] grams compared to 28.7 [27.1-29.1] weeks gestation and 1209 [1130-1220] grams in the Calmer group. In both groups, 3 out of the five infants were male. Other baseline characteristics were also similar between the two groups (see Table 1).

Minimal difference in mean heart rate was found between the two groups. The median [IQR] Mean HR at baseline, poke and recovery for the FT group was 158 [157-159] bpm, 186 [171- 
$188] \mathrm{bpm}$, and 169 [168-171] bpm respectively, compared to 159 [156-167] bpm, 173 [169-177] bpm, and 163 [155-169] bpm in the Calmer group. However, when the high frequency (HF) component of the HRV was calculated, a clear difference between the groups was evident. The infants in the Calmer group had a higher median [IQR] HF $\left(\mathrm{Hz} / \mathrm{ms}^{2}\right)$ at Baseline, Poke and Recovery of 36.0 [23.7-73.2], 2.2[1.1-3.0] and 6.8[1.7-21.1] respectively. In contrast, the FT group had a median [IQR] HF $\left(\mathrm{Hz} / \mathrm{ms}^{2}\right)$ of 3.6[3.1-9.1] at Baseline, 0.4[0.3-7.2] at Poke and 5.2[4.1-12.8] at Recovery. The absolute difference in $\mathrm{HF}\left(\mathrm{Hz} / \mathrm{ms}^{2}\right)$ between the groups at each time point was 32.3 at Baseline, 1.7 at Poke and 1.6 at Recovery. There was a similar trend when the low frequency (LF) component of the HRV as well. Table 2 displays the median[IQR] components of HRV as well as the absolute differences between each group at Baseline, Poke and Recovery. Figure 2 displays the HF changes across all three time points in both groups.

\section{Discussion:}

To the best of our knowledge, this randomized controlled pilot study is the first to report the initial feasibility of managing acute pain in preterm infants in the NICU with a novel medical robot invented by an occupational therapist and others meant to simulate pain mitigating components of skin-to-skin holding. Our invention utilized expert occupational therapy knowledge regarding the ways in which touch and sensory stimulation can alter early brain development. In this case, this knowledge was applied in a neonatal pain context.

Infants in the Calmer group had an $90 \%, 82 \%$ and $24 \%$ increased $\mathrm{HF}$ activation at Baseline, Poke and Recovery phases, respectively, compared to infants in the FT group. In addition to higher HF across all phases, Calmer infants had a heightened

responsiveness/variability of the autonomic system (it goes deeper to decrease and returns faster to higher values) compared to those in the FT group. Moreover, the trends for both HF and LF 
were similar. The greater difference from Baseline to Poke in LF in Calmer group indicated a more positive Calmer effect on increasing total variability of the heart rate (more variability is healthier). Thus, compared to infants who received FT, infants in the Calmer group appeared to have more optimal functioning of their ANS.

One infant within the FT group (FT 5) had a much higher HF response from poke to recovery, which was in contrast to all the other infants in the study. After an thorough chart review, a clinical/medical reason could not be ascertained for this response. Nor could we explain it as being related to any events that occured during the assessment as all the equipment functioned well. With this small sample size, we can not be sure that response was an outlier or if some other unknown influence affected the infant. Another infant also in the FT group (FT 3), had an interrupted recovery due to clinical care needs (see Figure 2), which potentially artificially increased the HRV. Both of these infants were included in the final analysis as intended. However, if these infants were to be excluded from the analysis, the benefit of Calmer is potentially greater, with up to a $40 \%$ increase of $\mathrm{HF}$ activation within the Recovery phase.

These preliminary results suggested a positive effect of Calmer for reducing acute painrelated procedural physiological stress experienced by preterm infants. Indeed, our results parallel findings in another controlled trial where a physical robot's breathing-like motion was able to produce a statistically significant calming effect in adults who hold the breathing robot in their lap so they could feel it (Sefidgar, et al., 2015). If Calmer is shown in larger studies to be efficacious, it represents a unique opportunity to expand our scope of potential brain protective practices for high risk infants. Moreover, Calmer may have applications beyond the NICU in other pediatric populations with whom occupational therapists work, such as for helping infants recover from surgery or for calming infants who may, for medical or neurodevelopmental 
reasons, have prolonged periods of agitation.

As is to be expected, the main limitation of this pilot study is the the small number of patients in each group, which means that, although there was a difference between the two groups, interpreting it statistically is not possible. Other considerations are also important. As others have reported, we found wide variation in the data. (e.g. Krueger, van Oostrom, \& Shuster, 2010), yet many studies describing HRV in preterm infants have used cohort designs. We have a used randomized design which aims to control variables that might otherwise influence outcomes; thus, the level of variation may be as a result of the low sample size and/or it may be related to sympathovagal immaturity in these preterm infants (e.g. McCain, LudingtonHoe, Swinth, \& Hadeed, 2005). A larger randomized clinical trial has just been completed that will allow us to evaluate the effect of Calmer on HRV with greater precision (unpublished data).

The length of time each group was provided treatment before the heel lance differed between groups. Because we were conducting the first pilot study, we were not able to alter what is the standard of care in our NICU for the length of time facilitated tucking is applied. Finally, since ECG data recordings during painful procedures may contain signals with movement artifacts as the infants respond to the stimulus, chosing the optimal analysis segments can be challenging. We made every attempt to chose segments as close to the phase markers as possible with as clean a signal as possible. Even with those considerations in mind, the greater percent differences in parasympathetic activation across all blood collection phases that were found in the infants who received Calmer treatment supported advancing the work on this technology.

\section{Conclusion:}

This randomised controlled pilot study suggests that Calmer shows promise for further 
development and evaluation to help reduce the multiple long-term effects of increased stress in preterm infants admitted to a NICU. Our work adds to the occupational therapy evidence base regarding effective early sensory interventions for hospitalized preterm infants and illustrates the initial steps taken for technology transfer in safety critical hospital settings. Capitalizing on these positive results, a larger, nationally-funded, randomised control-trial has just been completed which has evaluated in a larger sample, the impact of a revised prototype of Calmer for reducing stress in preterm infants in the next stage of transferring this novel technology into clinical care. 


\section{References}

Axelin, A., Salantera, S., \& Lehtonen, L. (2006). 'Facilitated tucking by parents' in pain management of preterm infants-a randomized cross over trial. Early Hum Devel, 82(4), 241-7.

Borovikova, L., Ivanova, S., Zhang, M., Yang, H., Botchkina, G., Watkins, L., . . Tracey, K. (2000). Vagus nerve stimulation attenuates the systemic inflammatory response to endotoxin. Nature, 405(6785), 458-462.

Brummelte, S., Grunau, R., Chau, V., Poskitt, K., Brant, R., Vinall, J., . . et, a. (2012). Procedural pain and brain development in premature newborns. Ann Neurol, 71, 385-396.

Carbajal, R., Lenclen, R., Jugie, M., \& et, a. (2005). Morphine does not provide adequate analgesia for acute procedural pain among preterm infants. Pediatrics, 115(6), 14941500 .

Cong, X., Cusson, R., Walsh, S., Hussain, N., Ludington-Hoe, S., \& Zhang, D. (2012). Effects of skin-to-skin contact on autonomic pain responses in preterm infant. J.Pain, 13(7), 636645.

Cong, X., Ludington-Hoe, S., McCain, G., \& Fu, P. (2009). Kangaroo Care modifies preterm infant heart rate variability in response to heel stick pain: pilot study. Early Hum.Dev, 85(9), 561-567.

Doesburg, S., Chau, C., Cheung, T., Moiseev, A., Ribary, U., Herdman, A., . . Grunau, R. (2013). Neonatal pain-related stress, functional cortical activity and visual-perceptual abilities in school-age children born at extremely low gestational age. Pain, 154(10), 1946-1952.

Franck, L., \& C, S. (2003). Parent visiting and participation in infant caregiving activities in a neonatal unit. Birth, 30, 31-35.

Grunau, R., Haley, D., Whitfield, M., Weinberg, J., Yu, W., \& Thiessen, P. (2007). Altered basal cortisol levels at 3, 6, 8 and 18 months in infants born at extremely low gestational age. J.Pediatr, 150(2), 151-156.

Grunau, R., Whitfield, M., Petrie-Thomas, J., Synnes, A., Cepeda, I., Keidar, A., . . Johannesen, D. (2009). Neonatal pain, parenting stress and interaction, in relation to cognitive and motor development at 8 and 18 months in preterm infants. Pain, 143(1), 138-146.

Holsti, L., Backman,. C, \& Engel, J. (2013). Occupational therapy. Oxford Textbook of Pediatric Pain. (P. McGrath, B. Stevens, S. Walker, \& W. Zempsky, Eds). Oxford University Press:Oxford, England. DOI. 10.1093/med/9780199642656.003.0057 
Holsti, L., \& Grunau, R. (2010). Is sucrose the solution? Considerations of sucrose for reducing procedural pain in preterm infants. Pediatrics, 125(5), 1042-1047.

Holsti, L., Weinberg, J., Whitfield, M., \& et, a. (2007). Relationships between adrenocorticotropic hormone and cortisol are altered during clustered nursing care in preterm infants born at extremely low gestational age. Early Hum Devel, 83(5), 341-348.

Huston, J., \& Tracey, K. (2011). The pulse of inflammation: heart rate variability, the cholinergic anti-inflammatory pathway and implications for therapy. J.Intern.Med, 269(1), 45-53.

Johnston, C., Barrington, K., Taddio, A., \& et, a. (2011). Pain in Canadian NICUs. Have we improved over the past 12 years? Clin J Pain, 27, 225-232.

Johnston, C., Fernades, A., \& Cambell-Yeo, M. (2011). Pain in neonates is different. Pain, 152, S65-S73.

Johnston, C., Filion, F., \& Campbell-Yeo, M. (2008). Kangaroo mother care diminished pain from heel lance in very preterm infants: A cross-over trial. BMC Pediatrics.

Krueger, C., van Oostrom, J.H., \& Shuster, J. (2010). A longitudinal description of heart rate variability in 28-34-week-old preterm infants, Biol Res Nurs, 11(3), 261-268.

March of Dimes. (2009). White paper on preterm birth. The global and regional toll. NY: White Plains.

McCain, G.C., Ludington-Hoe, S.M.,. Swinth J.Y., \& Hadeed, A.J. (2005). Heart rate variability responses of a preterm infant to kangaroo care. JOGNN, 34, 689-694.

McPherson, C., \& Grunau, R. (2014). Neonatal pain control and neurologic effects of anesthetics and sedatives in preterm infants. Clin Perinatol, 41(1), 209-227.

Moorman, J., Carlo, W., Kattwinkel, J., Schelonka, R., Porcelli, P., Navarrete, C., . . Michael O'Shea, T. (2011). Mortality reduction by heart rate characteristic monitoring in very low birth weight neonates: a randomized trial. J.Pediatr, 159(6), 900-6.

Morison, S., Holsti, L., Grunau, R., Whitfield, M., Oberlander, T., Chan, H., \& Williams, L. (2003). Are there developmental distinct motor indicators of pain in preterm infants? Early Hum Dev, 72(2), 131-146.

Oberlander, T.F., \& Saul, J.P. (2002). Methodological considerations for the use of heart rate variability as a measure of pain reactivity in vulnerable infants. Clin Perinatol, 29(3), 427-443. 
Parrish, W., Rosas-Ballina, M., Gallowitsch-Puerta, M., Ochani, M., Ochani, K., Yang, L., .. . Pavlov, V. (2008). Modulation of TNF Release by Choline Requires $\alpha 7$ Subunit Nicotinic Acetylcholine Receptor-Mediated Signaling. Mol Med, 14(9), 567-574.

Trembley, S., Ranger, M., Chau, C.M.Y, Ellegood, J., Lerch, J.P., Holsti, L. , Goldowitz, D., \& Grunau, R.E.(2017). Let's not sugar coat it: Long term adverse effects on the brain of repeated sucrose for pain management in preterm infants. Pain, 158, 1586-1598.

Sefidgar, Y., MacLean, K., Yohanana, S., Van der Loos, M., Croft, E., \& Garland, J. (2015). Design and evaluation of a touch-centered calming interaction with a social robot. Transactions on Affective Computing, 7(2), 108-121.

Smith, S., Haley, S., Slater, H., \& Moyer-Mileur, L. (2013). Heart rate variability during caregiving and sleep after massage therapy in preterm infants. Early Hum.Dev, 89(8), 525-529.

Smith, S., Lux, R., Haley, S., Slater, H., Beachy, J., Beechy, J., \& Moyer-Mileur, L. (2013). The effect of massage on heart rate variability in preterm infants. J.Perinatol, 33(1), 59-64.

Snedec, N., Simoncic, M., Klemenc, M., Ihan, A., Vidmar, I., \& Grosek, S. (2013). Heart rate variability of transported critically ill neonates. Eur.J.Pediatr, 172(12), 1565-1571.

Stevens, B., Gibbins, S., \& Franck, L. (2000). Treatment of pain in the neonatal intensive care unit. Pediatr Clin North Am, 47(3), 633-650.

Stevens, B., Pillai Riddell, R., \& Oberlander, T. (2007). Assessment of pain in neonates and infants. (3rd Ed ed.). (K. Anand, B. Stevens, \& P. McGrath, Eds.) Toronto: Elsevier.

Vinall, J., Miller, S., Chau, V., Brummelte, S., Synnes, A., \& et, al. (2012). Neonatal pain in relation to postnatal growth in infants born very preterm. Pain, 153, 1374-1381.

Ward-Larson, C., Horn, R., \& Gosnell, F. (2004). The efficacy of facilitated tucking for relieving procedural pain of endotracheal suctioning in very low birth weight infants. $M C N, 29$, 151-156.

Waxman, J.A., Pillai Riddell,R.R., Tablon, P., Schmidt, L.A., \& Pinhasov A. (2016). Development of cardiovascular indices of acute pain responding in infants: A systematic review. Pain Research \& Management, 2016, 2016, 8458696.

doi:10.1155/2016/8458696. 
Zwicker, J., Grunau, R., Adams, E., Chau, V., Brant, R., Poskitt, K., . . . et, al. (2013). Score for acute neonatal physiology-II and pain predict corticospinal tract development in premature newborns. Ped Neurol, 48, 123-129. 
Figure 1. Patient Flow Diagram 

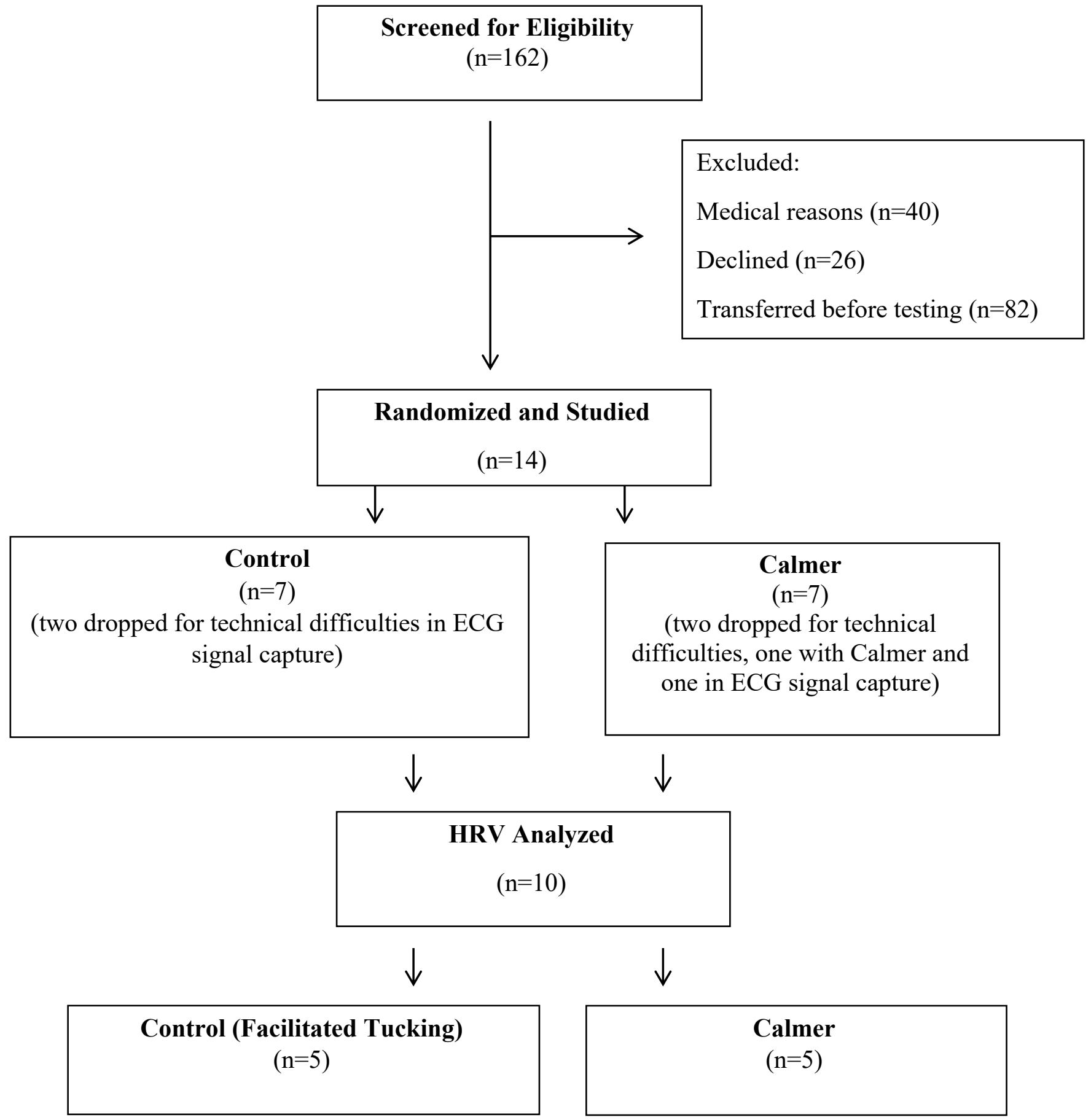
Figure 2. Heart Rate Variability Across Pain Procedure Phases 


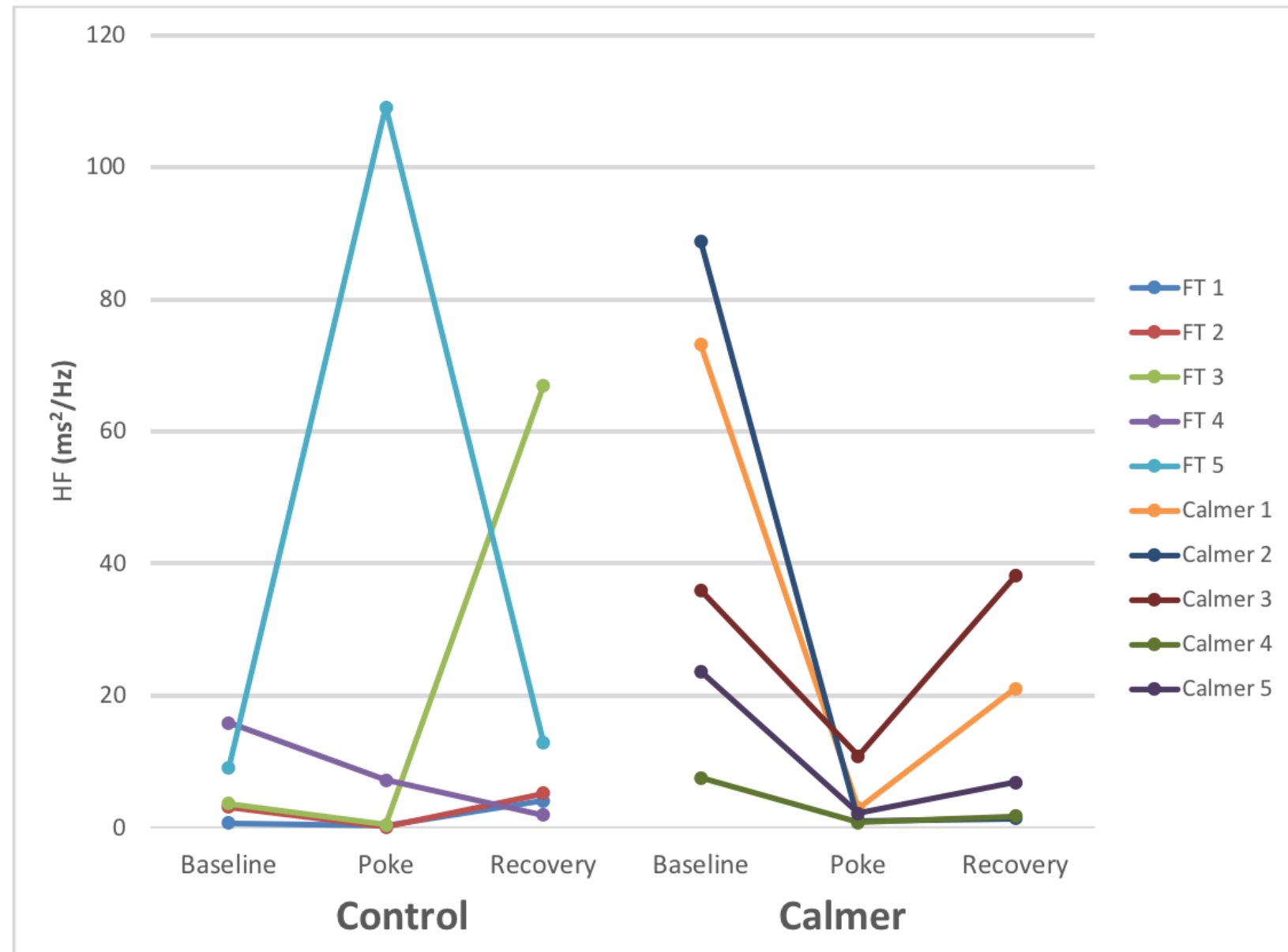


Table 1: Baseline Characteristics (Median [Inter Quartile Range])

\begin{tabular}{lccccc}
\hline Group & $\begin{array}{c}\text { Gestational } \\
\text { Age } \\
\text { (weeks) }\end{array}$ & $\begin{array}{c}\text { Birth } \\
\text { Weight } \\
\text { (grams) }\end{array}$ & $\begin{array}{c}\text { Age at } \\
\text { assessment } \\
\text { (days) }\end{array}$ & $\begin{array}{c}\text { Maternal } \\
\text { age at } \\
\text { delivery } \\
\text { (years) }\end{array}$ & $\begin{array}{c}\text { Minutes } \\
\text { infant fed } \\
\text { before study }\end{array}$ \\
\hline FT & 28.1 & 1235 & 25 & 24 & 30 \\
$(\mathbf{n = 5})$ & {$[27.7-28.9]$} & {$[1194-1390]$} & {$[22-29]$} & {$[22-28]$} & {$[30-30]$} \\
$\begin{array}{l}\text { Calmer } \\
(\mathbf{n = 5})\end{array}$ & 28.7 & 1209 & 14 & 33 & 75 \\
& {$[27.1-29.1]$} & {$[1130-1220]$} & {$[11-27]$} & {$[29-35]$} & {$[60-120]$} \\
\hline
\end{tabular}


Table 2: Median [InterQuartile Range] of the different components of Heart Rate Variability (HRV:Hertz/ms ${ }^{2}$ ) at each time point.

\begin{tabular}{|c|c|c|c|c|c|c|}
\hline HRV & Group & Baseline & Poke & Recovery & $\begin{array}{c}\text { Difference } \\
\text { Baseline - } \\
\text { Poke }\end{array}$ & $\begin{array}{c}\text { Difference } \\
\text { Poke - } \\
\text { Recovery }\end{array}$ \\
\hline \multirow[t]{3}{*}{ HF } & FT & $\begin{array}{c}3.6 \\
{[3.1-9.1]}\end{array}$ & $\begin{array}{c}0.4 \\
{[0.3-7.2]}\end{array}$ & $\begin{array}{c}5.2 \\
{[4.1-12.8]}\end{array}$ & -3.2 & 4.8 \\
\hline & Calmer & $\begin{array}{c}36.0 \\
{[23.7-73.2]}\end{array}$ & $\begin{array}{c}2.2 \\
{[1.1-3.0]}\end{array}$ & $\begin{array}{c}6.8 \\
{[1.7-21.1]}\end{array}$ & -33.8 & 4.6 \\
\hline & Difference & 32.6 & 1.8 & 2.7 & & \\
\hline \multirow[t]{3}{*}{ LF } & FT & $\begin{array}{c}11.6 \\
{[9.4-25.1]}\end{array}$ & $\begin{array}{c}4.2 \\
{[3.1-6.2]}\end{array}$ & $\begin{array}{c}48.8 \\
{[15.9-66.5]}\end{array}$ & -7.4 & 44.6 \\
\hline & Calmer & $\begin{array}{c}85.9 \\
{[56.1-141.3]}\end{array}$ & $\begin{array}{c}15.0 \\
{[1.5-28.1]}\end{array}$ & $\begin{array}{c}33.8 \\
{[32.0-119]}\end{array}$ & -70.9 & 18.8 \\
\hline & Difference & 67.5 & 11.4 & 17.9 & & \\
\hline
\end{tabular}

$\mathrm{N}=5$ for both the Calmer and FT groups.

$\mathrm{HRV}=$ Heart rate variability, $\mathrm{HF}=$ High frequency power, $\mathrm{LF}=$ Low frequency power, FT=Facilitated Tucking 